\title{
Awareness of Assuit University Students about Self-Medication
}

Fatma M. Hamza ${ }^{1}$, Soad A. sharKawy ${ }^{2}$ \& Naglaa S. Abd EL Aty ${ }^{3}$.

1. Nursing Specialist in El-Shamia Tropical Hospital at Sahel Seilem, Egypt.

2. Assistant Professor of Community Health Nursing Assiut Universit, Egypt.

3. Assistant Professor of Community Health Nursing Assiut Universit, Egypt.

\begin{abstract}
Background: Self-medication is a common and regular practice of using medicines without any medical supervision by the people themselves for self-treatment. Aim of this study: to assess knowledge and reported practices of university students regarding self-medication and determine the prevalence of self-medication among university students at Assuit University. Subjects and Methods: a descriptive cross sectional study was used in this study which conducted at four faculties of Assiut University among 1035 of fourth grad who were selected through simple random sample. Two tools were utilized for data collection: Tool I: A structured self-administered questionnaire Tool II: to assess reported practices of self-medication among university students. Results: It was found that $76.2 \%$ of studied students were females and the prevalence rate of self-medication among them was $90.4 \%$ also $71.4 \%$ of them reported that fast solution to relieve pain was the most common reason for using self-medication. $84.4 \%$ and $62.1 \%$ of studied students had unsatisfactory knowledge and reported practices regarding self -medication. Conclusions: The prevalence of self-medication was high among university students in Assuit University. Most of studied students had un satisfactory knowledge and reported practices about self- medication. Recommendation: Periodic health education programs regarding self-medication are needed to enhance awareness among studied students.
\end{abstract}

\section{Keywords: Self-medication, University Students \& Awareness.}

\section{Introduction}

Self-medications or over the counter (OTC) drugs at this time play a major role in self-care, offering individuals the choice of making independent decisions regarding their own health. The WHO has also pointed out that responsible self-medication can help prevent and manage conditions that do not require consultation with a physician and provides a cheaper alternative for treating common problems (Azhar et al., 2013).

The World Health Organization has defined self-medication as "use of pharmaceutical or medicinal products by a consumer to treat selfrecognized disorders or symptoms, the intermittent or continued use of medication previously prescribed by a physician for chronic or recurring disease or symptom, or use of medication recommended by lay sources or health workers not entitled to prescribe medicine (Uppal et al., 2014).

Self-medication is influenced by age, gender, education level, family, society, medical knowledge, perception of illness, self-care orientation and drug advertisements (Afolabi, 2008). The increase in selfmedication was due to a number of factors like socioeconomic factors, lifestyle, ready access to drugs, the increased potential to manage certain illnesses through self- care, and greater availability of medicinal products. Patient contentment with the healthcare provider and cost of the drugs (Abay \& Amelo, 2010).
There are many public and professional concerns about misuse of drugs. The prevalence rate is high all over the world up to $68 \%$ in European countries, $57 \%$ in USA, $92 \%$ in adolescence of Kuwait $31 \%$ in India, 59\% in Nepal 51\% in Pakistan 55\% in medical students in University of Ain Shams in Egypt and $62.9 \%$ in medical students in University Mansoura, Egypt (Rajput \& Mathur, 2010), (Helala \& AbouEl-Wafa, 2017) ).

The practice of self- medication is a crisis, as people are using whatever they think has got medicinal content without knowledge of the effects associated with that particular medicine; thus, lack of knowledge on the effects or risks of self-medication are paying significantly to the practice of self -medication. As a result of this people develop severe harmful effects from the medicines and delay themselves in seeking medical care at the hospital, thereby complicating their conditions (Afolabi, 2012).

Among commonly used non-prescribed medicines are antacids, stool softeners, anti-diarrheal, cold and allergy remedies, pain relievers, antipyretics, antibiotics, antispasmodics, vitamins, nutritional supplements, cough medicines and stimulants (Alshanqiti \& Almoshaddk, 2016).

The cost of negative outcomes as a consequence of self-medication may include wastage of resources, increased resistance of Pathogens and serious health hazards such as adverse reactions and drug interactions. The availability of the more complex 
drugs such as antibiotics without prescriptions is a source of great concern. Antimicrobial resistance is a current problem worldwide particularly in developing countries where antibiotics are often available without a prescription (Sherazi et al., 2012).

Community health nurses as healthcare providers and community members are involved in self-medication. For example, nurses are commonly asked by the public to administer injectable medicines that are obtained without prescription like pain relievers and antibiotics. In such cases nurses should ask for prescriptions otherwise they should not administer the medication. Community health nurses are responsible for correcting public malpractices regarding self-medications. They play an important role in guarding the public against irrational use of medicines, and disseminating reliable pharmacological and non-pharmacological advice and information (WHO 2014).

\section{Significance of the study}

Self-medication is an increasing public heath problem world wide while a limited number of drug utilization studies have been conducted in Egypt. In Alexandria, a phamaco-epidemiological study about self-medication among adults attending pharmacies reported that nearly $81 \%$ of medications were purchased without prescription (Sallam et al., 2009) Another study carried out among Ain Shams University medical students in Cairo, Egypt, showed that the prevalence of self - medication among the studied population was 55\% (El Ezz \& Ez-Elarab, 2011)

Another study conducted by (Helala \& AbouEIWafa, 2017) in Mansoura University students in Cairo, Egypt and found that the prevalence of

self - medication among medical studied students was $62.9 \%$.

So the present study was conducted to assess knowledge and reported practices of university students regarding self-medication and determine the prevalence of self-medication among university students at Assuit University

\section{Research questions}

1- What is the prevalence of self-medication among Assiut university students?

2- Do the students have good knowledge about

3- self-medication?

4- Do students know the risks of self -medication?

5- Is there difference of self-medication practice in practical and theoretical faculty?

6- Is there association between socio-demographic characteristics of university students and their practice regarding self -medication?

\section{Subjects \& Methods Aim of study}

To assess knowledge and reported practices of university students regarding self-medication and determine the prevalence of self-medication among university students at Assuit University

\section{Research design}

A descriptive cross-sectional research design was used in this study.

\section{Setting}

This study was conducted at four randomly selected Faculties at Assiut University, two practical faculties (Faculty of pharmacy \& Faculty of nursing) and two theoretical faculties (Faculty of Commercial \& Faculty of arts) during the academic year 2017-2018

\section{Sampling}

A simple random sample was used to select the studied faculties in this study and a convenient sample was used in choosing the studied students Assiut University includes (18) faculties divided into (12) practical colleges and (6) theoretical colleges. This study was conducted at (4) faculties which selected randomly. Students of fourth grade were included in this study.

The total number of fourth year students in the selected faculties were 5730 students, by using software EPI /Info, version 3,3 with $99.9 \%$ confidence interval (CI), the final estimated sample size was 911students. To compensate the dropouts, $20 \%$ was added to the sample size; the final sample size was 1093 students; excluded from them 58 students because of incomplete answer and the final sample was 1035 the sample divided as $(70 \%$ of students) from theoretical faculties and (30\% of students) due to the number of students at theoretical faculties more than practical, It was divided as the following:

\begin{tabular}{|l|c|c|c|}
\hline \multicolumn{1}{|c|}{ Faculty } & $\begin{array}{c}\text { Total } \\
\text { number of } \\
\text { students }\end{array}$ & $\begin{array}{c}\text { Sample } \\
\text { size }\end{array}$ & $\begin{array}{c}\text { Sample } \\
\text { size after } \\
\text { drop out }\end{array}$ \\
\hline $\begin{array}{l}\text { Faculty of } \\
\text { commercial }\end{array}$ & 2165 & 385 & 354 \\
\hline Faculty of arts & 2247 & 385 & 377 \\
\hline $\begin{array}{l}\text { Faculty of } \\
\text { pharmacy }\end{array}$ & 855 & 163 & 161 \\
\hline $\begin{array}{l}\text { Faculty of } \\
\text { nursing }\end{array}$ & 463 & 160 & 143 \\
\hline Total & 5730 & 1093 & 1035 \\
\hline
\end{tabular}

\section{Tools of the study}

Two tools were used in the current study

Tool(1): A structured self-administered questionnaire was developed by researcher after reviewing related literature to collect information from the students, it was included two parts: 
Part 1: Socio-demographic characteristics: as age, sex, name of the faculty, parent's education and occupation.

Part 2: students' knowledge about self -medication it includes (9) questions such as definition of self-medication, rtype of self-medications used, indications for self -medication and risks of self medication.

\section{Scoring system of knowledge}

Questionnaire to assess the knowledge which contains two types of questions: the first type was statements to which respondents answer with either yes or no. The second type was open ended questions as reasons for taking self-medication type of

self-medications used, indications for

self-medication, risks of self-medication. The total grades of knowledge equal (20 points); a grade one was given for each correct answer and zero was given for an incorrect answer and I don't know. The grades for each item were summed and then converted into a percent score as the following

Unsatisfactory $=$ score $<60 \%$, and satisfactory $=$ score $>60 \%$.

Tool (2): This tool includes reported practice of self-medication among university students it includes (11) questions and statements such as, is self-medication was first line of your treatment? Did you ever give your prescription medicines to others? When your symptoms are relieved, will you discontinue your Prescription medicines by yourself? Will you checked expire date of medication? Places from which you can obtaining self-medication, Go to the doctor after taking self-medication, Tell the doctor about self-medication, Frequency of taking self-medication, Actions taking when complications of self-medication appear and Suggestion for reduce using self -medication.

\section{Scoring system of reported practice}

This part includes reported practice of

self-medication among university students. The reported practice contains two types of questions: the first type was questions to which respondents answer with either yes or no. The second type was open ended questions as Actions taking when complications of self-medication appear, Suggestions for reduce using self-medication. The total grades of practice equal (11points); a grade one was given for each correct answer and zero was given for an incorrect answer and I don't know. The grades for each item were summed and then converted into a percent score as the following

Unsatisfactory $=$ score $<60 \%$, and satisfactory $=$ score $>60 \%$.

Validity of tools

To evaluate the sheet validity, it was reviewed by panel of five experts from community and family health nursing staff at, Assiut University. The necessary modifications and clarifications of some questions were done.

Reliability of tools

A reliability analysis was carried out in order to examine the internal consistency of its questions. The value of Cronbach's alpha was 0.835 for knowledge, and 0.786 for practice implying that the instrument was consistent and reliable in achieving the study objectives.

Methods

A. Administrative design

Before conducting the study an official approval letter was obtained from the dean of Faculty of Nursing, Assiut University to the vice of University president for students' affairs of Assiut University and the Deans of each selected faculty. The letter included a permission to carry out the study and explained the purpose and the nature of the stud

\section{Ethical consideration}

The researcher followed all the ethical issues in conducting the research. Consent was secured orally from the participants who were willing to participate in the study. The participants were informed that participation in this study is voluntary; they can withdraw at any time during the study without giving reasons. The researchers have explained the aim of the study to all university students in the study sample. They reassured that any obtained information would be strictly confidential.

\section{B. Operational design}

Pilot Study:

A pilot study was carried out before starting data collection on $10 \%$ of studied students. It was included in the total sample of the research. The aims of pilot study were to test clarity, feasibility and consistency of the tools and to estimate the time needed for filling the form.

\section{Data collection Phase}

- Data were collected during the period from the first of March to the end of May 2017 two days per week

- The researchers introduces themselves to the vicedeans for students' affairs at each selected faculty, and reminded them to the nature and purpose of the study. Then, they asked the vice-deans for students' affairs to take a copy of the study schedules of fourth grades of the faculties which involved in this study.

- The researchers took oral permission of the teaching staff members who were responsible for the desired lectures or sections, depending on their persuasion, thinking and the nature of each faculty, and then the researchers asked about the preferred time for data collection, either at the beginning or at the end part of the selected section 
or lecture. Sometimes, the staff members took a copy from an official approval letter.

- The researchers introduced themseleves to the students and took oral permission of students and explained the purpose and the nature of the study and explained the main parts of the questionnaire to them. After that, the questionnaire was distributed to the students by the researchers.

- Students were asked to complete the questionnaire and were asked about any difficulty that might face during answering the questionnaire.

- The average time taken for completing questionnaires was around 15-20 minutes.
- After the students filling the questionnaire, the researchers collected the questionnaires with paying attention to incomplete answers to be completed by the student.

- Finally, the researchers thanked the students and teaching staff for their cooperation.

\section{Statistical analysis}

Data entry and data analysis were done using SPSS version 19 (Statistical Package for Social Science). Data were presented as number, percentage, mean and standard deviation. Chi-square test and Fisher Exact test were used to compare between qualitative variables. P-value considered statistically significant when $\mathrm{P}<0.05$.

\section{Results}

Table (1): Socio-demographic characteristics of the studied students at Assiut University 2017.

\begin{tabular}{|c|c|c|}
\hline Items & No. $(n=1035)$ & $\%$ \\
\hline \multicolumn{3}{|l|}{ Age: (years) } \\
\hline $20-22$ & 743 & 71.8 \\
\hline$>22$ & 292 & 28.2 \\
\hline Mean \pm SD (Range) & \multicolumn{2}{|c|}{$22.06 \pm 1.01(20.0-30.0)$} \\
\hline \multicolumn{3}{|l|}{ Sex: } \\
\hline Male & 246 & 23.8 \\
\hline Female & 789 & 76.2 \\
\hline \multicolumn{3}{|l|}{ Faculty name: } \\
\hline Faculty of Arts & 377 & 36.4 \\
\hline Faculty of Commerce & 354 & 34.2 \\
\hline Faculty of Nursing & 143 & 13.8 \\
\hline Faculty of Pharmacy & 161 & 15.6 \\
\hline \multicolumn{3}{|l|}{ Father education: } \\
\hline Illiterate & 93 & 9.0 \\
\hline Basic education & 205 & 19.8 \\
\hline Secondary education & 300 & 29.0 \\
\hline University education & 437 & 42.2 \\
\hline \multicolumn{3}{|l|}{ Mother education: } \\
\hline Illiterate & 236 & 22.8 \\
\hline Basic education & 197 & 19.0 \\
\hline Secondary education & 257 & 24.8 \\
\hline University education & 345 & 33.3 \\
\hline
\end{tabular}

Table (2): Knowledge of studied student about conditions of taking self-medication at Assiut University 2017.

\begin{tabular}{|l|c|c|}
\hline \multicolumn{1}{|c|}{ Conditions of taking self-medication: $(\neq)$} & No. $(\mathbf{n = 1 0 3 5})$ & \% \\
\hline Cold and flu treatment & 663 & 64.1 \\
\hline All kinds of Pain & 530 & 51.2 \\
\hline High temperature(fever) & 420 & 40.6 \\
\hline To treat epidermis and acne & 196 & 18.9 \\
\hline To treat hair problems & 149 & 14.4 \\
\hline To treat sleep disturbances and stress & 91 & 8.8 \\
\hline To treat anemia and physical weakness & 88 & 8.5 \\
\hline Don't know & 28 & 2.7 \\
\hline
\end{tabular}

(†) More than one answer was selected. 
Table (3): Relationship between total score of students' knowledge regarding self-medication and their sociodemographic characteristics at Assiut University 2017.

\begin{tabular}{|c|c|c|c|c|c|c|}
\hline & \multicolumn{4}{|c|}{ Knowledge level } & \multirow{3}{*}{$\mathbf{X}^{2}$} & \multirow{3}{*}{ P-value } \\
\hline & \multicolumn{2}{|c|}{$\begin{array}{c}\text { Unsatisfactory } \\
(n=874) \\
\end{array}$} & \multicolumn{2}{|c|}{$\begin{array}{c}\text { Satisfactory } \\
(n=161)\end{array}$} & & \\
\hline & No. & $\%$ & No. & $\%$ & & \\
\hline \multicolumn{5}{|l|}{ Age: (years) } & \multirow{3}{*}{16.91} & \multirow{3}{*}{$0.000 *$} \\
\hline $20-22$ & 649 & 87.3 & 94 & 12.7 & & \\
\hline$>22$ & 225 & 77.1 & 67 & 22.9 & & \\
\hline \multicolumn{5}{|l|}{ Sex: } & \multirow{3}{*}{0.30} & \multirow{3}{*}{0.582} \\
\hline Male & 205 & 83.3 & 41 & 16.7 & & \\
\hline Female & 669 & 84.8 & 120 & 15.2 & & \\
\hline \multicolumn{5}{|l|}{ Faculty: } & \multirow{5}{*}{99.40} & \multirow{5}{*}{$0.000 *$} \\
\hline Faculty of Arts & 345 & 91.5 & 32 & 8.5 & & \\
\hline Faculty of Commerce & 318 & 89.8 & 36 & 10.2 & & \\
\hline Faculty of Nursing & 115 & 80.4 & 28 & 19.6 & & \\
\hline Faculty of Pharmacy & 96 & 59.6 & 65 & 40.4 & & \\
\hline \multicolumn{5}{|l|}{ Father education: } & \multirow{5}{*}{2.11} & \multirow{5}{*}{0.550} \\
\hline Illiterate & 81 & 87.1 & 12 & 12.9 & & \\
\hline Basic education & 176 & 85.9 & 29 & 14.1 & & \\
\hline Secondary education & 256 & 85.3 & 44 & 14.7 & & \\
\hline University & 361 & 82.6 & 76 & 17.4 & & \\
\hline \multicolumn{5}{|l|}{ Mother education: } & \multirow{5}{*}{8.28} & \multirow{5}{*}{$0.041 *$} \\
\hline Illiterate & 208 & 88.1 & 28 & 11.9 & & \\
\hline Basic education & 161 & 81.7 & 36 & 18.3 & & \\
\hline Secondary education & 225 & 87.5 & 32 & 12.5 & & \\
\hline University & 280 & 81.2 & 65 & 18.8 & & \\
\hline
\end{tabular}

* Statistical significance difference at $p$ value $<0.05$.

Table (4): Relation between sex and practice of self-medication of different types of drugs among at Assiut University students 2017.

\begin{tabular}{|c|c|c|c|c|c|}
\hline \multirow{3}{*}{ Medicine $(\neq)$} & \multicolumn{4}{|c|}{ Sex } & \multirow{3}{*}{ P-value } \\
\hline & \multicolumn{2}{|c|}{$\operatorname{Male}(n=246)$} & \multicolumn{2}{|c|}{$\operatorname{Female}(n=789)$} & \\
\hline & No. & $\%$ & No. & $\%$ & \\
\hline Analgesic & 187 & 76.0 & 612 & 77.5 & 0.613 \\
\hline Cold and flu medication & 97 & 39.4 & 336 & 42.6 & 0.381 \\
\hline Antibiotic & 64 & 26.0 & 158 & 20.0 & $0.046^{*}$ \\
\hline Antipyretic & 27 & 11.0 & 191 & 24.2 & $0.000^{*}$ \\
\hline Antiacid medication & 7 & 2.8 & 33 & 4.2 & 0.342 \\
\hline Antidiarrha & 7 & 2.8 & 31 & 3.9 & 0.430 \\
\hline Vitamins & 4 & 1.6 & 15 & 1.9 & 1.000 \\
\hline Sedative medication & 3 & 1.2 & 2 & 0.3 & 0.090 \\
\hline Medication for anemia & 1 & 0.4 & 16 & 2.0 & 0.090 \\
\hline Nose drop & 2 & 0.8 & 5 & 0.6 & 0.673 \\
\hline For renal colic & 2 & 0.8 & 6 & 0.8 & 1.000 \\
\hline Other drugs & 5 & 2.0 & 8 & 1.0 & 0.203 \\
\hline
\end{tabular}

* Statistical significance difference at $p$ value $<0.05$. 


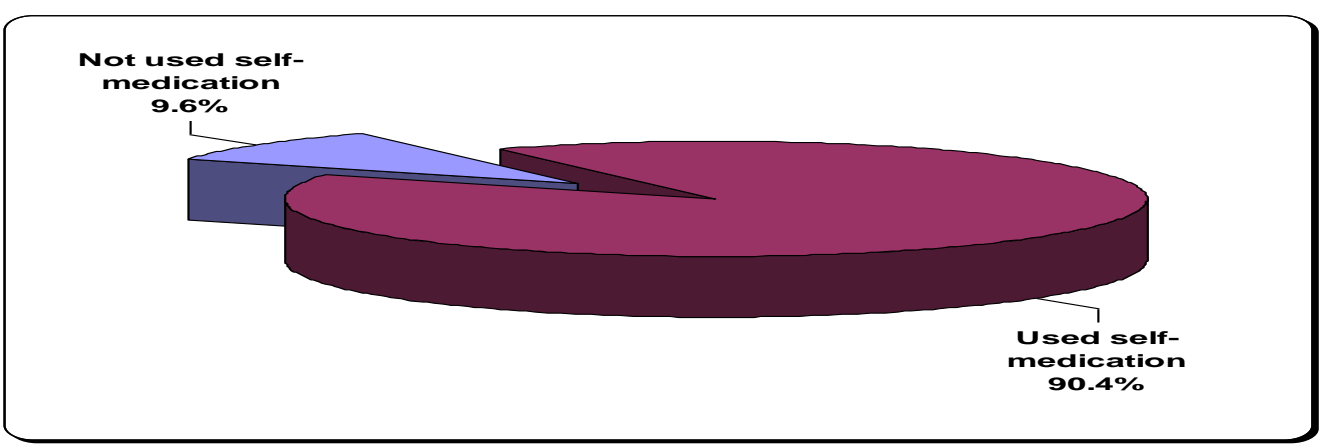

Fig (1): Prevalence of using self -medication among studied students at Assiut university 2017.

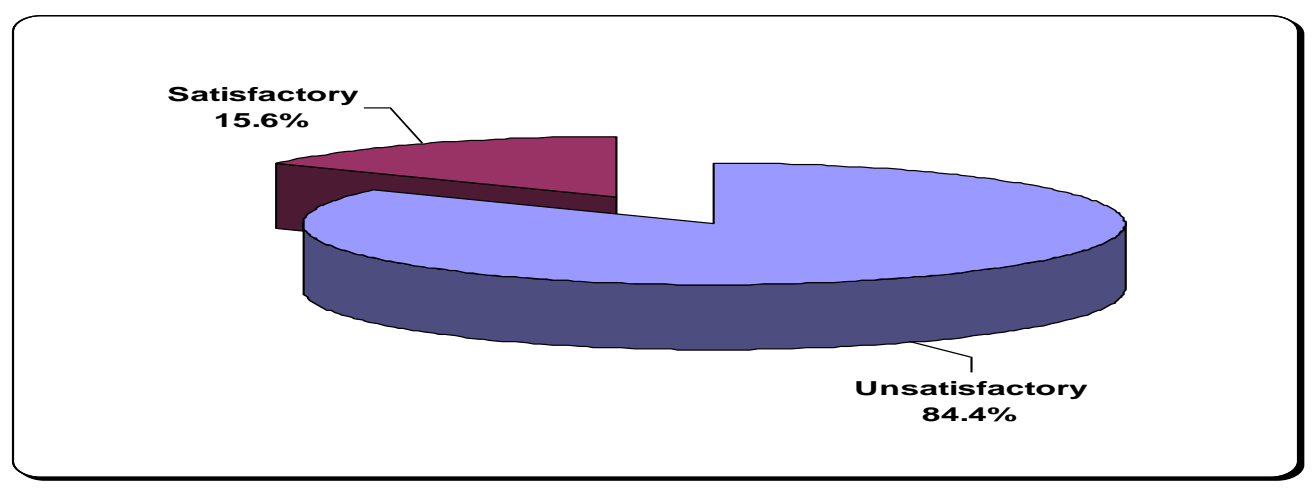

Fig (2): Total score of knowledge of studied students regarding self-medication at Assiut university2017.

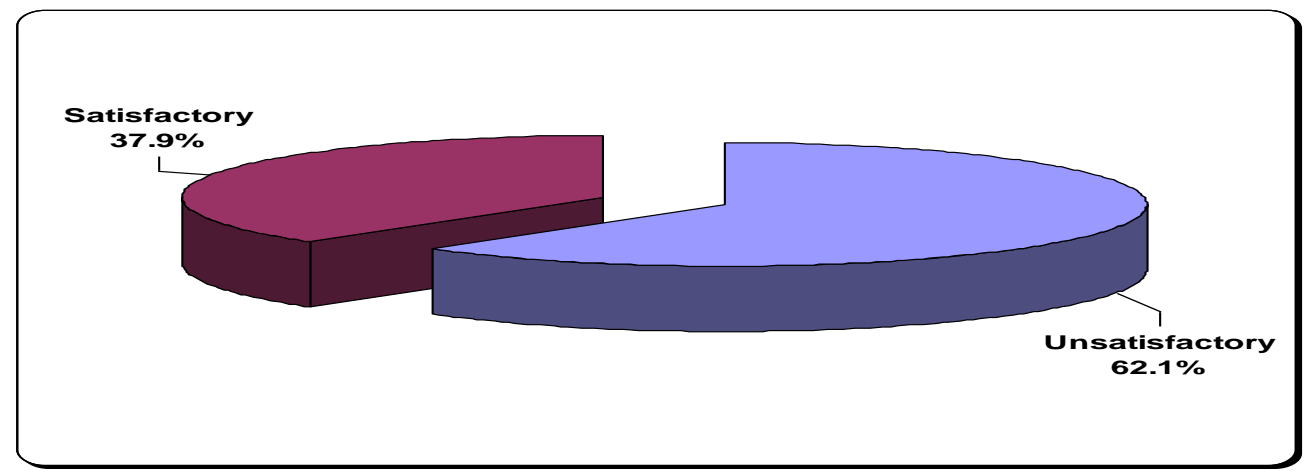

Fig (3): Total score of reported practice of studied students regarding self-medication at Assiut university 2017, $(n=1035)$.

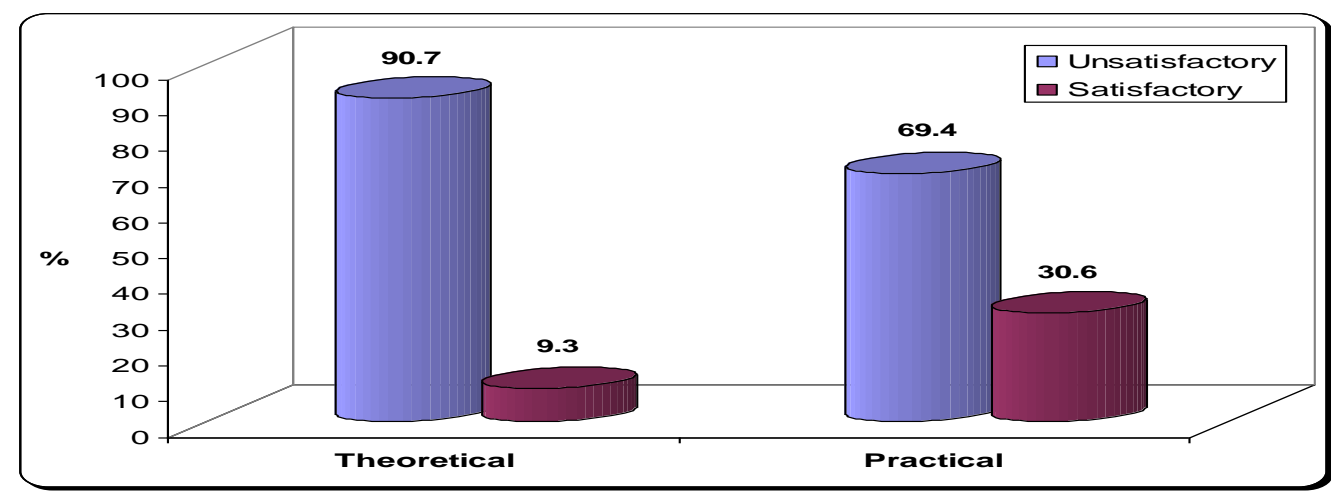

Fig (4): Relation between total score of students' knowledge and type of faculty regarding self -medication at Assiut university 2017. 
Table (1): Shows socio-demographic characteristics of the studied students, it was found that $71.8 \%$ of the studied students their age range from (20-22) years old. According to students sex it was observed that $76.2 \%$ of studied students were females and $23.8 \%$ of them were males. Regarding to parents' education it was found that $42.20 \%$ of father $33.3 \%$ of mothers had university education.

Table (2): Shows students' knowledge about conditions of taking self-medication, it was observed that $64.1 \%$ of the studied students mentioned that they took self-medication in conditions of cold and flu treatment and $51.2 \%$ of them mentioned that they took self-medication in conditions of all kinds of pain and only $2.7 \%$ of them mentioned that they hadn't know conditions of took self-medication.

Table (3): Shows the relationship between total score of students' knowledge regarding self-medication and their sociodemographic characteristics; it was cleared that the majority $87.4 \%$ of studied students aged (2022) years have unsatisfactory level of knowledge. Also this table revealed the majority $84.8 \%$ of studied female students have unsatisfactory level of knowledge.

On the other hand, this table revealed that pharmacy students' have satisfactory level of knowledge, (91.9\%, 89.8\% and $80.4 \%$ respectively of studied students on faculty of arts, commerce and nursing have unsatisfactory level of knowledge regarding self -medication. Also this table indicates that there was statistically significant difference between students score of knowledge regarding self-medication and type of faculty, their age and mothers education $\mathrm{p}=0.00, \mathrm{P}=00.0 \mathrm{P}=0.0$ 4respectively

Table (4): Reveals relation between sex and practice self-medication of different types of drugs among studied students at Assiut University, it was cleared that $(76.0 \%$ and $77.5 \%$ respectively) of male and female were taking analgesic. Also this table indicates that there was statistically significant difference between sex and practice self-medication of different drugs as antibiotic and antipyretic $\mathrm{p}=0.046-0.000$ respectively

Fig (1): Presents the prevalence of using self medication among studied students. It was revealed that $90.4 \%$ of studied students were used self medication and only $9.6 \%$ of them weren't used self medication.

Fig (2): Presents total score of knowledge of studied students regarding self-medication. It was revealed that $84.4 \%$ of studied students had un satisfactory knowledge regarding self -medication and only $15.6 \%$ of them had satisfactory knowledge.

Fig (3): Clear that total score of reported practice of studied students regarding self-medication. It was revealed that $62.1 \%$ of studied students had unsatisfactory reported practice regarding self medication while $37.9 \%$ of them had satisfactory practice.

Fig (4): Shows that relation between total score of students' knowledge and type of faculty regarding self-medication, it was found that $90.7 \%$ of theoretical students had unsatisfactory level of knowledge While, $69.4 \%$ of practical students had unsatisfactory level of knowledge regarding self medication.

\section{Discussion}

Self-medication is the selection and use of medicines by individuals to treat self-recognized illnesses or symptoms, as defined by the World Health Organization Self-medication is often due to the use of nonprescription medicines, commonly known as over the-counter (OTC) medication. (Mitra et al., 2018)

The aim of this study was to assess knowledge and practice of university students regarding selfmedication and determine the prevalence of selfmedication among university students at Assuit University.

The results of the current study show that more than two thirds of the studied students their age range from (20-22) years old this finding in line with

(Al Essa et al., 2019) who studied practice, awareness and attitude towards self- medication of analgesic among health science students in Riyadh in Saudia Arabia and referred that more than two third of the studied students their age range from (20-22) years.

According to the sex it was found that more than three quarters of studied students were females .This finding supported with (El Ezz \& Ez-Elarab, 2011) who studied Knowledge, attitude and practice of medical students towards self- medication at Ain Shams University in Egypt and reported that more than two thirds of the studied students were females.

According to type of faculty it found that more than one quarter of studied students were enrolled to practical faculties and more than two thirds of them were enrolled to theoretical faculties. This is because the number of students in theoretical faculties were more than the number of students in practical faculties.

The findings of the present study in agreement with (Ansam, 2008) who carried out a study on Assessment of Self-Medication Practice among University Students in Palestine: Therapeutic and Toxicity Implication and the studied sample was $(29.7 \%)$ of medical students and $(70.3 \%)$ of them were non- medical students

Regarding to students' knowledge about conditions of taking self-medication, the present study revealed 
that less than two thirds of the studied students mentioned that they took self-medication in conditions of cold and flu treatment.

The finding of the current study was similar also to (Helala \& Abou-EIWafa, 2017) who carried out study on Self-Medication in University Students from the City of Mansoura, Egypt and found that the most frequent conditions that were suitable for selfmedication from the students opinion were cold.

Concerning to prevalence of used self -medication it was found that the majority of the studied students were used self -medication, the present study agrees with (Alshogran et al., 2018) who conducted a study on Patterns of self-medication among medical and nonmedical University students in Jordan and they showed that the prevalence of self-medication was the majority.

Also, the finding of the current study in agreement with (Gyawali, et al., 2015) who studied knowledge, Attitude and Practice of Self-medication among Basic Science undergraduate medical students in a Medical school in Western Nepal and referred that prevalence of self-medication in their study was the majority.

According to the relation between total score of knowledge of studied students regarding self medication and type of faculty it was found that the majority of theoretical students had unsatisfactory level of knowledge While, 69.4\% of practical students had unsatisfactory level of knowledge regarding self-medication

This finding in the same line with (Gupta et al., 2011) in Malwa region of Punjab and verified that respondents of medical college students had good knowledge than non- medical college students.

According to relation between sex and practice selfmedication of different drugs among studied students at Assiut University, the present study indicated that there was statistically significant difference between sex and practice self-medication of different drugs as antibiotic and antipyretic , $\mathrm{p}=0.046-\quad 0.000$ respectively

The present study similar to (El eZZ, \& Ez-Elarab, 2011) and referred that there was statistical significant difference between males and females only as regards the vitamins and analgesics intake and herbal products intake $(\mathrm{p}=0.00, \mathrm{p}=0.002$ and $\mathrm{p}$ $=0.03$, respectively) .

The majority of studied students had unsatisfactory knowledge and reported practice this may be due to they hadn't know enough about self- medication because there weren't any heath education program about self- medication or because in this study the number of theoretical students more than practical students and theoretical students in their study didn't know more about medication or the long waiting time at clinics or hospitals and they needed quick decision to relive their problem or may be not face any complication from self- medication

\section{Conclusion}

The prevalence of self-medication was alarmingly high among university students in Assuit University. Most of studied students had unsatisfactory knowledge and practice about self- medication

The majority of the studied students were used self medication and the majority of them were take analgesic.

\section{Recommendations}

Periodic health education programs regarding self-medication are needed to enhance awareness among university students.

\section{References}

1. Abay S., \& Amelo W., (2010): Assessment of Self-Medication Practices among Medical, Pharmacy, and Health Science Students in Gondar University, Ethiopia, J Young Pharm, vol 2, (3): pp 306-310

2. Afolabi A., (2008): Factors influencing the pattern of self-medication in an adult Nigerian population. Ann Afr Med, vol 7, pp120-7.

3. Afolabi A., (2012): Self-Medication, Drug Dependency and Self-Managed Health Care - A Review pp224-232 available at:https://www.researchgate.net/publication /260983100 Afolabi AO 2012

4. Al Essa M., Alshehri A., Alzahrani M., Bustami R., Adnan S., Alkeraidees Alkeraidees A., Mudshil A., \& Gramish, (2019): practice awareness and attitude towards self- medication of analgesic among health science students in Riyadh in Saudia Arabia Pharmaceutical Journal 27pp 235-239

5. Alshanqiti A., \& Almoshaddk W., (2016): NON-prescription medication usage among adult females in two western cities in Saudi Arabia European, Journal of pharmaceutical and medical research vol 3(1) pp31 available from www.ejpmr.com 1

6. Alshogran O., Khabour K., \& Farah A., (2018): Patterns of self-medication among medical and nonmedical University students in Jordan Risk Management and Healthcare Policy Dovepress pp169-176

7. Azhar M., Gunasekaran K., Kadirvelu A., Gurtu S., Sadasivan S., \& Kshatriya B., (2013): Self -medication awareness and attitude among Malaysian urban population International Journal of Collaborative Research 
on Internal Medicine\& Public Health Vol. 5 No. 6 pp437

8. El Ezz N., Ez-Elarab H., (2011): Knowledge, attitude and practice of medical students towards self-medication at Ain Shams University, Egypt. J Prev Med Hyg 52:196-200. 24.

9. Gupta V., Bansal P., Manhas R., Singh Z., Ghaiye P., (2011): Preferred system of medicine and reasons of self-medication among college students in Malwa region of Punjab. J Drug Deliv and 1 (2) pp27-29.

10. Gyawali S., Shankar P., Poudel P., \& Saha A., (2015): Knowledge, Attitude and Practice of Self-medication among Basic Science Undergraduate Medical Students in a Medical School in Western Nepal. J Clin Diagn Res;9(12):FC17-FC22.

11. Helal R., Abou-Elwafa H., (2017): Selfmedication in university students from the city of Mansoura, Egypt. J Environ Public Health. pp 9145193.

12. Mitra A., Imtiaz A., Al-Ibrahim Y., Bulbanat M., Al-Mutairi M., Al-Musaileem F., (2018): Factors influencing knowledge and practice of self-medication among college students of health and non-health professions IMC J Med ; 12(2): PP:57-68.

13. Rajput M., \& Mathur V., (2010): Pharmacoepidemological study of selfmedication in Indore city. Indian journal of pharmacy practice.; vol3(1):pp25-30. Available from: http//ijopp.org/pdf/ijopp

14. Sallam S., Khallafallah N., Ibrahim N., \& Okasha A., (2009): Pharmacoepidemiological study of self-medication in adults attending pharmacies in Alexandria, Egypt. East Mediterr Health; vol 15 (3):pp 683-91. PMID:19731784

15. Sherazi B., Mahmood K., Amin F., Zaka M., Riaz M., \& Javed A., (2012): Prevalence and Measure of Self Medication: A Review journal of pharmaceutical science and research Vol.4(3), pp 1774-17

16. Uppal D., Agarwal M., \& Roy V., (2014): Assessment of knowledge Attitude and practice of self-medication among college students International Journal of Basic Pharmacology, Vol 3, (6), Pp 988

17. World Health Organization, (2014):

Self -medication, Journal of Rational Use of Medicine (6) pp 26. 